\title{
Linguagem de Programação e a elaboração de discursos científicos
}

\author{
Flávia Aparecida da Silva Zocoler, Verônica Gomes dos Santos ${ }^{2}$ \\ ${ }^{1}$ Mestrado em Ensino, História e Filosofia das Ciências e Matemática \\ Bolsista pela Universidade Federal do ABC (UFABC) \\ ${ }^{2}$ Grupo de Estudos e Pesquisa em Ensino e Aprendizagem de Ciências \\ Universidade Federal do ABC (UFABC) \\ Av. dos Estados, 5001. Bairro Bangu. Santo André - SP - Brasil \\ flazocoler@gmail.com, veronicagsantos@yahoo.com.br
}

\begin{abstract}
This paper describes the work for the production of authorial, collaborative and scientific speeches developed with Elementary School $5^{\text {th }}$ grade students, done based on the creations performed in Scratch programming language, such as games and animations. The texts, animations and games will be part of the digital magazine which will be divulged for students from other regions of Brazil and 2 more countries, in a communication project, with the objective of divulging the built knowledge.
\end{abstract}

Resumo. Este artigo descreve o trabalho de produção de discursos autorais, colaborativos e científicos desenvolvido com alunos do $5^{\circ}$ ano do ensino fundamental I, feito com base nas criações realizadas a partir da linguagem de programação Scratch, como animações e jogos. Os textos, animações e jogos produzidos farão parte da revista digital que será divulgada para alunos de outras regiões do Brasil e outros 2 países, num projeto de comunicação, com o objetivo de divulgar os conhecimentos construídos.

\section{Introdução}

Apesar de encontrarmos diretrizes e referenciais que subsidiam e orientam o ensino de ciências na Educação Básica, é comum vermos os conteúdos científicos sendo abordados de modo instrucional e pouco envolvente para alunos que possuem a curiosidade e o interesse pela área instigada naturalmente. Partindo deste cenário, buscou-se criar condições para que os conteúdos previstos pudessem fomentar a produção autoral de textos científicos, de forma significativa e funcional, tanto para a escrita, como para os conteúdos tratados, tendo como pano fundo o desafio de colaborar para a construção de discursos científicos e uma postura ativa, desde os primeiros anos da Educação Básica.

Buscando viabilizar o almejado, foi estipulado como objetivo geral, investigar as possibilidades e desafios do trabalho com produção de textos científicos utilizando

II Congresso Brasileiro de Informática na Educação (CBIE 2015)

XIX Workshop de Informática na Escola (WIE 2015) 
recursos tecnológicos, para a formação de escritores competentes na língua materna, conscientes de que a produção textual visa à comunicação e a difusão do conhecimento.

E como forma de condução mais pontual os seguintes objetivos específicos

- Utilizar a linguagem de Programação Scratch como meio para sistematizar o conteúdo abordado.

- Investigar os desafios e potencialidades do ensino da produção de textos de forma contextualizada para auxiliar os alunos a compreenderem a Ciência como parte do dia-a-dia.

- Criar condições para que o conhecimento científico seja difundido através da produção escrita entre os estudantes envolvidos na pesquisa.

- Analisar se o trabalho interdisciplinar entre Ciências e Língua Portuguesa, utilizando recursos tecnológicos, contribui para o desenvolvimento de uma postura investigativa, científica, crítica e argumentativa dos alunos.

Desta forma, o que se segue busca discutir, fundamentar e encaminhar metodologicamente o desenvolvimento projeto para o alcance de tais metas e objetivos.

\section{Fundamentação}

Conhecer os caminhos e motivações que justificam o investimento no desenvolvimento do discurso científico a partir do uso das NTIC é um começo viável para alicerçar tais investidas. Rivard (1994) fala sobre a importância da escrita como forma de comunicação em Ciências, pois segundo o autor, escrever é fundamental não apenas para aprender alguma coisa, mas para criar respostas a problemas reais relacionados ao conhecimento adquirido. Ele considera que a contribuição da escrita para a aprendizagem está no desafio cognitivo envolvido nesta tarefa, que obriga os alunos a reprocessar conceitos, a formular hipóteses, a interpretar, sintetizar e confrontar ideias. Por isso é fundamental proporcionar, desde cedo, situações em que os alunos possam produzir discursos, tanto orais quanto escritos, com o objetivo de externar o conhecimento que constroem.

Desta forma, segundo Carvalho, Silva e Pimenta (2014) a escrita pode ser compreendida como ferramenta de aprendizagem e não apenas como meio de comunicação. Para estes autores, escrever, para além de favorecer atitudes positivas dos alunos, promove a aprendizagem ao obrigá-los a dar respostas às expectativas, convenções e formas de raciocínio próprio da escrita científica. Contribui assim para a promoção da aprendizagem podendo ser usada para desenvolver conceitos, generalizar, estimular o pensamento crítico, a resolução de problemas e refletir sobre o próprio processo de compreensão.

Os Parâmetros Curriculares Nacionais (2006) apontam para a necessidade de garantir no Ensino Fundamental o domínio da língua materna oral e escrita, já que é por meio dela que "o homem se comunica, tem acesso a informação, expressa e defende pontos de vista, partilha e constrói visões de mundo e produz conhecimento".

II Congresso Brasileiro de Informática na Educação (CBIE 2015)

XIX Workshop de Informática na Escola (WIE 2015) 
Neste ponto há uma convergência entre os objetivos propostos pelo PCN para o ensino de Ciências e Língua Portuguesa, já que é por meio do aprendizado da Língua Portuguesa que o aluno poderá conhecer a linguagem da natureza e comunicar os conhecimentos construídos.

Todavia algumas práticas em salas de aula apresentam um distanciamento muito grande entre estas disciplinas, tratando-as de maneira isolada.

O ensino de Ciências pode servir como aliado para o desenvolvimento da leitura e da escrita, já que ela atribui sentidos e significados para as palavras e discursos. Neste caso a escola precisa valorizar a pesquisa, a elaboração do discurso, a argumentação e a autoria.

Segundo Demo (2010), o desafio da autoria na escola está na necessidade dos alunos melhorarem seu texto, aprimorando sua argumentação. Para que isso aconteça é preciso ultrapassar o instrucionismo e estimular o discurso científico autoral. A escola deve tornar-se um ambiente adequado para a experimentação e circulação da linguagem científica. Constituir-se espaço para o estudo, pesquisa, elaboração, argumentação e fundamentação. Desafios devem ser propostos numa didática da problematização.

Através da interdisciplinaridade a tarefa de aprender a produzir textos torna-se significativa, pois desta forma é possível estabelecer conexões entre os conhecimentos construídos socialmente e a razão pela qual se escreve. Habilidades importantes como observação, análise e comparação, inerentes as Ciências, podem contribuir para o processo de aprendizagem da escrita.

O ensino de Língua Portuguesa tem muito a ganhar com a utilização das novas tecnologias como instrumentos facilitadores de aprendizagem, compreendidas como geradoras de oportunidades para que se alcance um novo saber pelas múltiplas oportunidades de interação, proporcionadas pelo uso das máquinas.

A melhor maneira de aprender a utilizar a língua é a partir de situações reais de uso. A tecnologia traz para a sala de aula a possibilidade, segundo Braga (2012), de formas dinâmicas, colaborativas e reflexivas de ensinar e aprender. Além disso, proporciona o desenvolvimento de habilidades para as negociações fundamentais num processo colaborativo de construção do conhecimento.

Para Júnior (2011), as redes informatizadas facilitam a parceria por meio de trabalho colaborativo e, por conseguinte, estimulam a solidariedade.

A tecnologia possibilita um trabalho muito próximo ao que é produzido socialmente. Proporciona, por exemplo, uma nova maneira de lidar com os erros na escrita. Segundo Júnior (2003), a rapidez e a facilidade em se revisar textos, permite que os alunos reflitam sobre seus erros, tornando-os significativos para o processo de aprendizagem.

De acordo com Júnior (2003, p.35)

II Congresso Brasileiro de Informática na Educação (CBIE 2015)

XIX Workshop de Informática na Escola (WIE 2015) 
CBIE-LACLO 2015

Anais do XXI Workshop de Informática na Escola (WIE 2015)

O computador traz uma tecnologia que facilita o tratamento dos erros. A rapidez, aliada à capacidade de repetição quase infinita, permite que os usuários possam refazer seus trabalhos antes de traduzi-los em arte final.

O trabalho com a Língua Portuguesa deve proporcionar ao aluno a clareza de que não são proprietários da língua, que é o lado público e coletivo da linguagem humana.

O papel do professor é fundamental neste processo. É ele quem vai mediar a produção, a construção do conhecimento e a interação entre os autores.

A escrita colaborativa, segundo Braga (2012), embora seja uma forma eficiente de aprender a língua, ainda é pouco explorada em sala de aula. Este tipo de produção textual permite a alternância de papéis por parte dos alunos, que ora são autores, ora, leitores e críticos do texto escrito. Além disso, facilita o processo de reescrita, que permite diversos arranjos textuais e seleções lexicais, fundamentais para $o$ amadurecimento da competência escritora. Tal prática pode contribuir para a formação de usuários competentes da Língua.

Espera-se que ao longo de sua escolaridade os alunos adquiram a competência linguística necessária para resolver problemas da vida cotidiana, ter acesso aos bens culturais e participar ativamente do mundo letrado.

\section{As linguagens de programação como uma das contribuições da tecnologia para a produção autoral}

Iniciado por Seymour Papert com o Logo no fim da década de 60 o trabalho com Linguagens de Programação vem ganhando um espaço privilegiado na educação, e mais recentemente no Ensino Fundamental I, com a chegada de linguagens voltadas a este público, como o Scratch desenvolvido por Mitchel Resnick do MIT - Massachusetts Institute of Technology, em 2007. O crescente interesse de educadores desta modalidade em questão se dá principalmente pela possibilidade do trabalho com a produção do aluno, através de um ciclo de criação (Valente, 2005), conforme representado na figura 1 , que favorece a aprendizagem colocando em destaque a autoria e o protagonismo infantil.

A resposta conseguida com o trabalho com as Linguagens de Programação atrelada ao currículo programático na educação surpreende principalmente pelo envolvimento dos alunos, independente dos temas abordados, pois a posição assumida por estes é totalmente inversa a forma passiva com que muitas vezes se relacionam com conteúdo e a tecnologia de modo geral. Neste sentido, se torna essencial considerar que "é preciso proporcionar aos alunos, desde muito cedo, a oportunidade de colocar em jogo situações onde é possível refletir, testar, argumentar, comprovar, refutar hipóteses a partir de projetos significativos e funcionais a sua formação, assumindo uma postura proativa, autoral e dinâmica" (Santos, Sobreira e Takinami, 2013).

II Congresso Brasileiro de Informática na Educação (CBIE 2015)

XIX Workshop de Informática na Escola (WIE 2015) 
CBIE-LACLO 2015

Anais do XXI Workshop de Informática na Escola (WIE 2015)



Figura 1 - Organograma sobre o ciclo de aprendizagens. Sobreira, Takinami e Santos (2013)

Desta forma, o que é colocado em jogo no processo de criação a partir de linguagens de programação, como o Scratch, é mais que a reprodução de conteúdos repassados automaticamente através de leitura e reprodução textual ou exercícios de verificação da compreensão. Neste sentido, o que se propõe é oferecer condições para que o aluno se coloque em um papel ativo, onde o que será aprendido, apesar de fazer parte do programa planejado pelo professor, surja da necessidade inerente ao se dispor a criar, sejam animações, simulações ou jogos, afinal, como destaca Silva, 2007.

Aquilo que a criança aprendeu porque fez, após ter explorado, investigado e descoberto por si própria, além de contribuir para o desenvolvimento de suas estruturas cognitivas, reveste-se de um significado especial que ajuda a reter e transferir com muito mais facilidade aquilo que foi aprendido. Está imbuído na filosofia do Logo, como concebeu Papert, a ideia que a aquisição de um conhecimento não se dá em função do desenvolvimento, mas principalmente na maneira pelas quais as pessoas se relacionam com o meio, ou seja, as condições que este oferece para exercitar o pensamento qualitativo. Acredita na necessidade da pessoa controlar sua aprendizagem, poder reconhecer e escolher entre várias possibilidades de pensamento estruturado. (Silva, 2007, p. 2).

Destes processos estruturados a partir da investigação, argumentação, produção autoral e colaborativa se dá a construção do conhecimento de forma significativa e contextualizada para os alunos, pois nasce de uma motivação intrínseca, de conhecimentos prévios, rumo à construção de um produto socialmente significativo e pertecente ao rol de interesses deste grupo, nascido em uma sociedade tecnológica e usuária quase que de forma transparente destes recursos.

II Congresso Brasileiro de Informática na Educação (CBIE 2015)

XIX Workshop de Informática na Escola (WIE 2015) 
Assim, ao compreender o papel da escrita na formação do discurso científico, como expressividade do conhecimento construído de forma colaborativa e autoral, entende-se que o mesmo pode fazer parte do cotidiano do aluno, independente da faixaetária, bastando apenas ser instigado e promovido a partir de condições propícias, onde o aluno se veja no papel ativo e visualize seus interlocutores como personagens reais. Em tempo, é preciso ainda considerar que, apesar da possibilidade de autoria se tornar cada vez mais comum no Ensino Fundamental I, é preciso criar condições para que os enredos do fazer científico nasçam da necessidade do aluno em conhecer mais sobre o assunto, seja por curiosidade ou por motivação surgida de uma proposta interessante, como o apresentado por Sobreira, Nunes e Morassi (2013) em versão anterior do WIE.

A criança é curiosa por natureza. Cabe a escola aguçar esta curiosidade, ser um espaço de troca, onde o estudante poderá aprender a formular perguntas, testar hipóteses e articular ideias com informação. Desta forma irá estabelecer as bases para o pensamento científico, estimulando o discurso mais sistemático, criativo e autônomo.

A educação científica é um direito do aluno e cabe à escola buscar uma nova maneira de ensinar, mais criativa e transformadora.

\section{Metodologia}

A presente pesquisa aconteceu na área educacional, caracterizada por abertura para a subjetividade e interpretação. Desta forma a metodologia empregada neste trabalho tomou como base uma pesquisa com abordagem empírica e qualitativa, a partir da prática pedagógica docente aplicada em uma turma do $2^{\circ}$ ano do ciclo II do Ensino Fundamental I de uma escola municipal.

Este trabalho teve como objetivo analisar as possibilidades e desafios do uso da escrita colaborativa na construção do discurso científico no $2^{\circ}$ ano do ciclo II do Ensino Fundamental, a partir dos referenciais teóricos selecionados. Para tanto, foram planejadas e aplicadas atividades sobre conteúdos de Ciências, incluindo a utilização de recursos tecnológicos para sua execução.

O planejamento das atividades foi realizado em consonância com o PPP da UE, que prevê os objetivos a serem atingidos durante o ano/ciclo, bem como os conteúdos a serem trabalhados. Foram propostas atividades de produção de textos colaborativos, revisão dos textos produzidos e a criação de um folder para divulgação dos conhecimentos construídos. A sequência de atividades foi desenvolvida nos 2 primeiros trimestres de 2015 utilizando os recursos das TIC, para o desenvolvimento e aprimoramento do discurso escrito.

Foram utilizados recursos tecnológicos disponíveis nos laptops educacionais e o laboratório de informática. Para a produção dos jogos e animações foi utilizado o Scratch como linguagem de programação e para a escrita de textos colaborativos foi utilizado o Google Drive.

II Congresso Brasileiro de Informática na Educação (CBIE 2015)

XIX Workshop de Informática na Escola (WIE 2015) 


\section{Desenvolvimento}

Os alunos já haviam estudado alguns sistemas do corpo humano e sabiam que cada um desenvolve uma função no organismo do ser vivo. Ao serem questionadas sobre as funções essenciais para a manutenção da vida, citaram, dentre outras, a necessidade da reprodução para a manutenção da espécie.

Diante da curiosidade e dos conhecimentos prévios, por vezes conflitantes, sobre o sistema reprodutor, foi sugerido aos alunos que, em grupos, escolhessem um subtema para realizar uma pesquisa mais estruturada para socializar com os demais. A forma de sistematização e socialização seria através da construção de um jogo ou animação, partindo do interesse nato desta faixa-etária por utilizar recursos desta natureza, tal como o fazem no cotidiano fora da escola.

O trabalho teve início em sala de aula, com uma roda de conversa sobre os diversos sistemas do corpo humano. As crianças já haviam construído, em um ano anterior com um projeto sobre as regiões brasileiras, o conceito de animação utilizando o Scratch como linguagem de programação. No laboratório de informática, tiveram os primeiros contatos de forma livre com o Scratch para a criação de jogos tendo como suporte alguns tutoriais impressos e vídeo-aulas para uso autônomo e a presença da Pape (responsável pelo laboratório de Informática educacional) para orientação.

A partir deste momento as etapas seguintes seguiram de acordo com a necessidade de cada grupo, que ora se dividia, ora trabalhava integralmente, estipulando prioridades. As etapas foram:

- Pesquisa na Internet e livros do acervo da biblioteca da escola

- Busca e seleção de imagens

- Edição de imagens

- Criação de storyboard para a construção dos jogos ou animações

- Programação dos jogos ou animações

- Publicação no site do Scratch

II Congresso Brasileiro de Informática na Educação (CBIE 2015)

XIX Workshop de Informática na Escola (WIE 2015) 


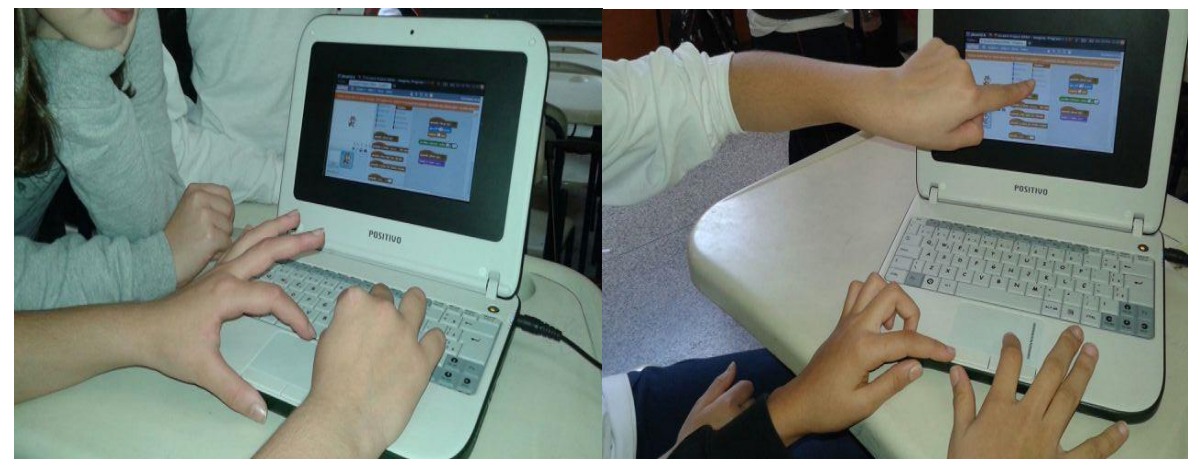

Figura 2 - Exploração inicial do Scratch

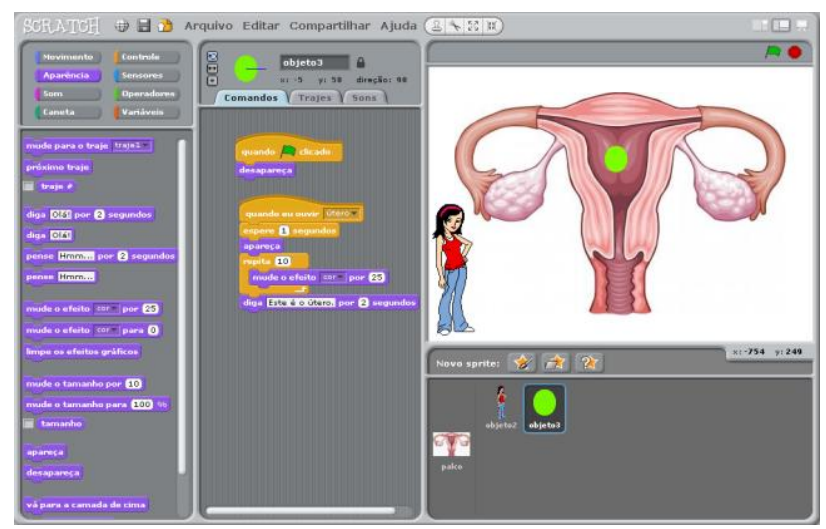

Figura 3 - tela inicial de uma das animações sobre o sistema reprodutor feminino

Com a finalização da construção dos jogos e animações a etapa da experimentação foi a que mais instigou os alunos. Além de colocar a prova todo o conhecimento construído através de pesquisas, seleção, negociação, tratamento e transformação da informação sobre o tema, os alunos se colocaram nos papéis de avaliados e avaliadores, simultaneamente, ao explorarem ativamente a construção do outro e levantarem as dificuldades e destaques do produto construído, no tocante à produção do objeto educacional.

Em relação aos conteúdos abordados, após a socialização das produções, as descobertas foram partilhadas numa roda de conversa e as informações apresentadas foram divididas em categorias, estabelecidas segundo critério da turma.

Desta forma foram criados no Google Drive os seguintes documentos:

- Para que serve o Sistema Reprodutor

- Quais são os órgãos que formam o Sistema Reprodutor

- Características do desenvolvimento do Sistema Reprodutor feminino

- Características do desenvolvimento do Sistema Reprodutor masculino

- Doenças relacionadas ao Sistema Reprodutor

II Congresso Brasileiro de Informática na Educação (CBIE 2015)

XIX Workshop de Informática na Escola (WIE 2015) 
- Cuidados para a manutenção da saúde

Os alunos foram divididos em grupos e cada um deu início à redação do texto sobre cada categoria criada. Numa segunda etapa os textos foram agrupados em um único documento do Google Drive, e toda turma, de maneira colaborativa e simultânea, produziu o a redação final a ser publicada na Revista digital própria para o projeto e que será hospedada no blog que compartilha e socializa a diversidade de propostas desenvolvidas por turmas de 5 escolas de localidades diferentes (http://escolasemfronteiras.com/) . Um folder também foi criado para divulgar a publicar a publicação da revista.

\section{Conclusões}

No que diz respeito ao trabalho com linguagens de programação e o uso dos recursos tecnológicos, foi observada uma maior autonomia e motivação em ampliar as pesquisas e aprofundar o leque de informações necessárias para a construção dos jogos e animações, como almejado no objetivo geral deste projeto. A partir do momento em que os alunos sentem-se autores e capazes de criar produtos socialmente funcionais e pertencentes ao cotidiano significativo destes, o interesse e compromisso em produzir algo de qualidade os move em busca do conhecimento construído de modo ativo. Em relação a elaboração dos discursos científicos observou-se um maior interesse em produzir textos coerentes e coesos, já que estes teriam uma função real de comunicação, ao serem publicados na revista digital.

Desta forma os alunos buscaram aprimorar suas produções por meio de várias revisões, que objetivavam adequar o texto, a fim de atingir uma escrita final que despertasse o interesse do leitor e comunicasse o que a turma considerava relevante. $\mathrm{O}$ uso da tecnologia facilitou este processo, já que possibilitou a escrita e revisão coletiva, bem como a pesquisa de dados de maneira colaborativa e síncrona. A criação de jogos e animações contribuiu para a elaboração do discurso oral, pois criou a necessidade de que os alunos partilhassem as informações pesquisadas, argumentassem e confrontassem ideias e opiniões acerca dos assuntos estudados. A construção do discurso oral, que precedeu a elaboração do discurso escrito, facilitou sua elaboração.

Percebe-se assim que, de modo geral, os objetivos estipulados inicialmente subsidiaram o projeto, contribuindo para o desenvolvimento crescente e gradual na formação de leitores, escritores e produtores autorais e autônomos, garantindo ainda, uma continuidade implícita projetada na postura ativa e protagonista, que passou a refletir e a influenciar produções além das previstas no projeto e, por conseguinte nas obras e metas futuras.

\section{Referências Bibliográficas}

II Congresso Brasileiro de Informática na Educação (CBIE 2015)

XIX Workshop de Informática na Escola (WIE 2015) 
BRAGA, D. B. Ambientes digitais. Coleção trabalhando com... na escola. São Paulo: Ed. Cortez, 2012.

BRASIL. Ministério da Educação. Secretaria da Educação Fundamental. Parâmetros Curriculares Nacionais de Língua Portuguesa. Secretaria de Educação Básica: Brasília (DF), 2006 v.II

BRASIL. Ministério da Educação. Secretaria da Educação Fundamental. Parâmetros Curriculares Nacionais de Ciências Naturais. Ministério da Educação. Secretaria de Educação Básica: Brasília (DF), 2006 v.IV

CARVALHO, J. A. B., SILVA, A.C e PIMENTA, J. Uso da Escrita em Diferentes Disciplinas Escolares: Construção ou reprodução de conhecimento? Universidade do Minho III Encontro de Reflexão sobre o Ensino da Escrita Disponível em http://repositorium.sdum.uminho.pt/bitstream/1822/9755/1/antonio\%20prof.pdf Acesso em 14/10/2014

DEMO, P. Educação e Alfabetização Científica. São Paulo: Papirus, 2010.

JÚNIOR, Fernando Moraes Fonseca. Informática para a mudança na educação. Ministério da Educação. USP 2003.

JUNIOR, F. M. F . Aprendendo com projetos. Brasília: Estapalavra/USP. 2011

SILVA, R.M. da. (2007) O uso da linguagem Logo na educação infantil. Artigo Acadêmico - Universidade Federal de Mato Grosso (UFMT). Disponível em http://www.sucesumt.org.br/mtdigital/anais/files/OUsodaLinguagemdeProgramacao Logo.pdf. Acesso em Maio de 2015.

SOBREIRA, E.S.R; NUNES, M.C; MORASSI S.B. Produzindo histórias não lineares: um incentivo à produção escrita e leitura, através do uso contextualizado da tecnologia. $19^{\circ}$ Workshop de Informática na Escola, Unicamp, campinas, 2013. Disponível em http://www.brie.org/pub/index.php/wie/article/view/2641. Acesso em Maio de 2015

SOBREIRA, E.S.R.; TAKINAMI, O. K.; SANTOS, V. G. (2013). Programando, criando e inovando com o Scratch: em busca da formação do cidadão do século XXI. Jornada de Atualização em Informática na Educação, 2, 126-152.

RIVARD, L. P. (1994). A review of writing to learn in science: Implications for practice and research. Journal of Research in Science Teaching, Canada. 31, 969983. Disponível em: http://migre.me/myUXd Acesso em 14/10/2014

VALENTE, J. A. (2005) Pesquisa, comunicação e aprendizagem com o computador. $O$ papel do computador no processo ensino-aprendizagem. Salto para o futuro. Disponível em http://portal.mec.gov.br/seed/arquivos/pdf/1sf.pdf. Acesso Maio de 2015

II Congresso Brasileiro de Informática na Educação (CBIE 2015)

XIX Workshop de Informática na Escola (WIE 2015) 